Gut and Liver, Vol. 10, No. 1, January 2016, pp. 51-57

\title{
Assessment of Factors Affecting the Usefulness and Diagnostic Yield of Core Biopsy Needles with a Side Hole in Endoscopic Ultrasound-Guided Fine-Needle Aspiration
}

Tadahisa Inoue, Fumihiro Okumura, Takashi Mizushima, Hirotada Nishie, Hiroyasu Iwasaki, Kaiki Anbe, Takanori Ozeki, Kenta Kachi, Shigeki Fukusada, Yuta Suzuki, and Hitoshi Sano

Department of Gastroenterology, Gifu Prefectural Tajimi Hospital, Gifu, Japan

Background/Aims: A barbed puncture needle with a side hole was recently developed to improve sample quality and quantity in endoscopic ultrasound-guided fine-needle aspiration (EUS-FNA). In this study, we retrospectively assessed the usefulness of this puncture needle. Methods: Factors affecting diagnostic yield, safety, and diagnostic accuracy were investigated in 76 patients who consecutively underwent EUS-FNA for neoplastic lesions at our hospital between January and December 2013. Results: The procedure was successful in all cases; the rates of sample collection and determination of the correct diagnosis were $92.1 \%$ and $89.5 \%$, respectively. The mean number of needle passes required for diagnosis was 1.1. Complications included mild intraluminal bleeding in two patients (2.6\%). Multivariate analysis revealed that lesion size ( $\leq 20 \mathrm{~mm}$ ) was significantly associated with a decreased chance of determining the correct diagnosis. Conclusions: Core biopsy needles with a side hole are safe and provide a satisfactory diagnostic yield. However, the side hole may potentially reduce the rate of making the correct diagnosis in small lesions. (Gut Liver 2016;10:51-57)

Key Words: Endoscopic ultrasound-guided fine needle aspiration; Biopsy needles; Side hole; Size of lesions

\section{INTRODUCTION}

Endoscopic ultrasound-guided fine-needle aspiration (EUSFNA) is a procedure that was first described by Vilmann et al. ${ }^{1}$ in 1992. It is useful in the pathological diagnosis of neoplastic lesions such as pancreatic tumors, gastrointestinal submucosal tumors, and lymph node lesions. Its diagnostic yield is high, as exemplified by sensitivity of $64 \%$ to $95 \%$, specificity of $75 \%$ to $100 \%$, and rate of correct diagnosis of $75 \%$ to $95 \%$ reported for pancreatic tumors. ${ }^{2-4}$ Complications of the procedure include bleeding, perforation, pancreatitis, and infection, but their frequencies are low, and thus, EUS-FNA is recognized as a safe procedure. ${ }^{5}$ In addition to efficacy and safety, the procedure is minimally invasive and is therefore supported around the world, gaining popularity within a short period of time since its development. On the other hand, various measures have been adapted to further increase its capacity in generating a correct diagnosis, such as improving the procedure and devices and processing pathological samples. Recently, the core biopsy needle (EchoTip ${ }^{\circledR}$ ProCore $^{\mathrm{TM}}$; Cook Medical Inc., Bloomington, IN, USA) was developed with the aim of enabling effective tissue sampling using a few punctures by improving sample quality and quantity. In contrast to the conventional needles (standard needle, SN), this core biopsy needle has a side hole called "Core Trap," and the tissue is scraped off the needle using the side hole when it is pulled by hand, instead of collecting the sample from the tip of the needle. In this study, we investigated the factors that affect the diagnostic yield of the ProCore ${ }^{\mathrm{TM}}$ needle (PN) in addition to its usefulness and safety.

\section{MATERIALS AND METHODS}

A retrospective analysis was conducted in 76 consecutive patients who underwent EUS-FNA with PN for neoplastic lesions at our hospital between January and December in 2013. A linear-array echoendoscope, GF-UCT260, with EU-ME1 processor (Olympus Medical Systems Corp., Tokyo, Japan) was used. With regard to the choice of puncture needle size at our hospital, 19-gauge is generally used because we believe that collection of larger samples reduces the burden on pathologists and increases

Correspondence to: Tadahisa Inoue

Department of Gastroenterology, Gifu Prefectural Tajimi Hospital, 5-161 Maebatacho, Tajimi, Gifu 507-8522, Japan

Tel: +81-572-22-5311, Fax: +81-572-25-1246, E-mail: tinoue-tag@umin.ac.jp

Received on July 7, 2014. Revised on August 30, 2014. Accepted on September 29, 2014. Published online May 13, 2015

pISSN 1976-2283 eISSN 2005-1212 http://dx.doi.org/10.5009/gnl14249

@) This is an Open Access article distributed under the terms of the Creative Commons Attribution Non-Commercial License (http://creativecommons.org/licenses/by-nc/4.0) which permits unrestricted non-commercial use, distribution, and reproduction in any medium, provided the original work is properly cited. 
the chances of generating a correct diagnosis. Nevertheless, a 22-gauge needle was selected when the manuaverability of the needle was poor because of the puncture site. The puncture procedure was done as follows: after visualizing the lesion by ultrasound, color Doppler imaging was conducted to confirm that there were no intervening blood vessels, and the puncture was performed. After puncturing the lesion, the stylet was removed and $10 \mathrm{~mL}$-syringe was attached to the puncture needle. A negative pressure of $10 \mathrm{~mL}$ was created, and the tissue was collected by performing 10 to 15 strokes within the lesion. To take advantage of the characteristics of PN designed to scrape off the tissue from the side hole while simultaneously preventing contamination from this hole, an effort was made to keep the side hole within the lesion. After removing the puncture needle from the endoscope, the stylet was again inserted into the puncture needle and the sample was pushed onto a glass slide. Since rapid on-site cytological examination is not available at our hospital, the puncture was repeated up to 4 times when the volume of the collected sample was considered insufficient macroscopically. With regard to sample processing, precisely cut fragments from the collected sample were placed in a formalin bottle and lined up in parallel to form a plane as uniform as possible. A paraffin block of the sample was then prepared and histologically assessed. The remaining liquid components and small tissue fragments were collected with a dropper and placed in a spitz tube, and a centrifugal smear was prepared using the autosmear method and assessed by cytologic diagnosis.

For the patients who underwent surgery, the final pathological diagnosis was confirmed by the examination of the resected specimet. For those who did not underwent surgery, the final diagnosis was made after follow-up for at least 6 months.

The primary outcome of the present study was correct diagnosis. Also, the sample collection rate, sensitivity, specificity, positive predictive value (PPV), negative predictive value (NPV), and accuracy were evaluated. In addition, the number of needle passes required to reach a diagnosis, the percentage of tissues that could be histologically diagnosed, and the incidence of complications were assessed. Puncture needle size, puncture route, number of passes, location of lesions, and size of lesions were investigated as factors that affect correct diagnosis. Size of lesions was classified as follows: $\leq 20 \mathrm{~mm}, 21-25 \mathrm{~mm}$, 26-30 mm, 31-35 mm, 36-40 mm, and $\geq 41 \mathrm{~mm}$ and examined by category. All patients gave their written informed consent before EUS-FNA. The study was approved by the Institutional Review Board of our hospital.

The results are expressed as percentages. Continuous variables are presented as the mean, range, and standard deviation. Factors that affect the generation of a correct diagnosis were examined using the chi-square test or Fisher exact test, and univariate analysis of continuous variables was performed using the Mann-Whitney test. For variables with a p-value of $\leq 0.2$ in the univariate analysis, multivariate analysis was performed using logistic regression analysis. A significant difference was detected when $\mathrm{p}<0.05$.

\section{RESULTS}

The mean age of the subjects ( 50 males and 26 females) was $69.5 \pm 9.9$ years (range, 39 to 86 years). The puncture route was transesophageal in two patients, transgastric in 47, transduodenal in 24, and transrectal in three. The target lesions were lymph node lesions in 15 patients, submucosal tumors in 19, pancreatic tumors in 34, and others in eight patients (adrenal tumors in three patients, liver tumors in two, lung tumor in one, and intra-abdominal masses in two). The mean lesion size was $30.9 \pm 16.4 \mathrm{~mm}$ (range, 15 to $80 \mathrm{~mm}$ ). The final diagnoses of patients with lymph node lesions were malignant lymphoma in six patients, lymph node metastases in five, sarcoidosis in two, and reactive enlargement in two. For patients with submucosal tumors, the final diagnoses were gastrointestinal stromal tumor (GIST) in nine patients, leiomyoma in six, submucosal tumorlike gastric carcinoma in two, and diagnosis unknown in two. For patients with pancreatic tumors, the final diagnoses were adenocarcinoma in 26 patients, autoimmune pancreatitis in five, chronic pancreatitis in two, and malignant lymphoma in one. For patients with other conditions, the final diagnoses were adrenal malignant lymphoma in two patients, adrenal adenoma, hepatocellular carcinoma, intrahepatic cholangiocarcinoma, and lung squamous cell carcinoma in one each, and peritoneal metastases of cancer in other organs in two (Table 1). In addition, assessment of the final diagnosis was performed using surgical samples for six patients. For the remaining patients, assessment was based on their clinical progress after at least 6 months.

The puncture procedure was successful in all patients (76/76). The sample collection rate was 92.1\% (70/76), and of these, histologic diagnosis could be obtained in 89.5\% (68/76), whereas only cytologic assessment and diagnosis was performed for two patients. In the final diagnosis, pancreatic cancer was false negative for two patients; however, correct diagnosis was obtained for the remaining patients. Correct diagnosis, i.e., when histologic diagnosis and cytologic diagnosis were combined, was $89.5 \%$ (68/76). In the patients from whom samples could be collected, sensitivity, specificity, PPV, NPV, and accuracy were 96.3\% (52/54), 100\% (16/16), 100\% (52/52), 88.9\% (16/18), and $97.1 \%$ (68/70), respectively. With regard to complications, intraluminal bleeding was observed in two patients, and the rate of occurrence was 2.6\% (2/76). However, it was mild and stopped naturally in both patients.

The mean number of needle passes required for diagnosis was $1.10 \pm 0.35$ passes (range, 1 to 3 passes). The percentage of patients in whom diagnosis was possible after the first puncture was $81.6 \%(62 / 76)$, and the cumulative correct diagnosis was $88.2 \%$ (67/76) when added to the five patients for whom diagnosis was possible after the second puncture. One patient 
required a third puncture, which made the cumulative correct diagnosis $89.5 \%$ (68/76). There was no patient for whom diagnosis was obtained by the fourth puncture (Table 2).

With regard to puncture needle size, 19-gauge was used in

Table 1. Baseline Characteristics of the Patients and Their Lesions

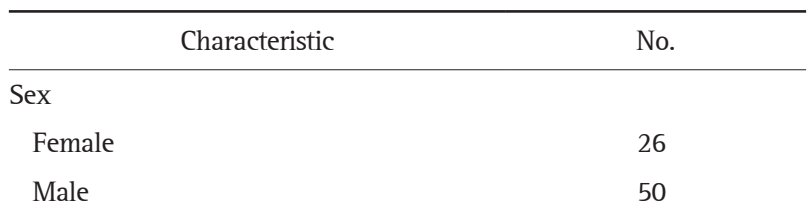

Age, yr

$69.5 \pm 9.9(39-86)$

Needle size, gauge

19

31

22

Puncture route

$\begin{array}{lr}\text { Transesophageal } & 2 \\ \text { Transegastric } & 47 \\ \text { Transduodenal } & 24 \\ \text { Transrectal } & 3\end{array}$

Size of lesion, mm

$30.9 \pm 16.4(15-80)$

Location of lesion and final diagnosis

Lymph node

Malignant lymphoma

Metastatic carcinoma

Sarcoidosis

Benign reactive lymphadenopathy

Submucosal tumor

GIST

Leiomayoma

Adenocarcinoma

Unknown

2

2

6

2

2

Pancreatic tumor

Adenocarcinoma
Autoimmune pancreatitis
Nonspecific inflammation
Malignant lymphoma

Others

Adrenal tumor
Malignant lymphoma
Adenoma
Liver tumor
Hepatocellular carcinoma
Cholangiocellular carcinoma
Lung tumor
Squamous cell carcinoma
Intra-abdominal masses
Metastatic carcinoma

Data are presented as number or mean \pm SD (range). GIST, gastrointestinal stromal tumor.
31 patients and 22-gauge in 45 patients. The respective correct diagnoses were 96.8\% (30/31) and 84.4\% (38/45), showing a decreased tendency with 22-gauge, although the difference was not significant $(\mathrm{p}=0.180)$. Correct diagnosis by the puncture route was $91.5 \%$ (43/47) for the transgastric route and 83.3\% (20/24) for the transduodenal route, showing a slightly low tendency for the transduodenal route; however, no significant difference was detected $(\mathrm{p}=0.434)$. Correct diagnosis by location of lesions was 93.3\% (14/15), 89.5\% (17/19), and 85.3\% (29/34) for the lymph node lesions, submucosal tumors, and pancreatic tumors, respectively (Table 3).

In the examination by size of lesions (Table 4), $\leq 20 \mathrm{~mm}$ was observed in 31 patients, $21-25 \mathrm{~mm}$ in eight, $26-30 \mathrm{~mm}$ in 13 , $31-35 \mathrm{~mm}$ in six, $36-40 \mathrm{~mm}$ in five, and $\geq 41 \mathrm{~mm}$ in 13 . The respective correct diagnoses were 77.4\% (24/31), 100\% (8/8), 100\% (13/13), 83.3\% (5/6), 100\% (5/5), and 100\% (13/13). Except for one patient, the lesion sizes of patients who could not be diagnosed were $\leq 20 \mathrm{~mm}$. Therefore, we investigated the

Table 2. Pathological Analysis of Specimens Obtained with Endoscopic Ultrasound-Guided Fine-Needle Aspiration Using a Core Biopsy Needle

\begin{tabular}{lc}
\hline \multicolumn{1}{c}{ No. of passes } & Cumulative correct diagnosis $(\mathrm{n}=76)$ \\
\hline 1 & $62(81.6)$ \\
2 & $67(88.2)$ \\
3 & $68(89.5)$ \\
4 & $68(89.5)$ \\
No. of passes for diagnosis & $1.10 \pm 0.35(1-3)$ \\
\hline
\end{tabular}

Data are presented as number (\%) or mean \pm SD (range).

Table 3. Diagnostic Performance of Endoscopic Ultrasound-Guided Fine-Needle Aspiration Using a Core Biopsy Needle according to Subgroups

\begin{tabular}{lcccc}
\hline & $\begin{array}{c}\text { No. of } \\
\text { patients }\end{array}$ & $\begin{array}{c}\text { Obtained } \\
\text { material for } \\
\text { diagnosis }\end{array}$ & $\begin{array}{c}\text { Adequate } \\
\text { sample for } \\
\text { histologic } \\
\text { analysis }\end{array}$ & $\begin{array}{c}\text { Correct } \\
\text { diagnosis }\end{array}$ \\
\hline Needle size, gauge & & & & \\
$\quad 19$ & 31 & $30(96.8)$ & $30(96.8)$ & $30(96.8)$ \\
22 & 45 & $40(88.9)$ & $38(84.4)$ & $38(84.4)$ \\
Puncture route & & & & \\
$\quad$ Transegastric & 47 & $45(95.7)$ & $43(91.5)$ & $43(91.5)$ \\
$\quad \begin{array}{l}\text { Transduodenal } \\
\text { Others }\end{array}$ & 24 & $20(83.3)$ & $20(83.3)$ & $20(83.3)$ \\
Location of lesion & 5 & $5(100.0)$ & $5(100.0)$ & $5(100.0)$ \\
$\quad$ Lymph node & 15 & $14(93.3)$ & $14(93.3)$ & $14(93.3)$ \\
$\quad$ Submucosal tumor & 19 & $17(89.5)$ & $16(84.2)$ & $17(89.5)$ \\
$\quad$ Pancreatic mass & 34 & $31(91.2)$ & $30(88.2)$ & $29(85.3)$ \\
Others & 8 & $8(100.0)$ & $8(100.0)$ & $8(100.0)$ \\
\hline
\end{tabular}

Data are presented as number (\%). 
Table 4. Diagnostic Performance of Endoscopic Ultrasound-Guided Fine-Needle Aspiration Using a Core Biopsy Needle with Respect to the Size of the Lesion

\begin{tabular}{lrccc}
\hline $\begin{array}{c}\text { Size of } \\
\text { lesion, mm }\end{array}$ & $\begin{array}{c}\text { No. of } \\
\text { patients }\end{array}$ & $\begin{array}{c}\text { Obtained } \\
\text { material for } \\
\text { diagnosis }\end{array}$ & $\begin{array}{c}\text { Adequate sample } \\
\text { for histologic } \\
\text { analysis }\end{array}$ & $\begin{array}{c}\text { Correct } \\
\text { diagnosis }\end{array}$ \\
\hline$\leq 20$ & 31 & $26(83.9)$ & $26(83.9)$ & $24(77.4)$ \\
$21-25$ & 8 & $8(100.0)$ & $7(87.5)$ & $8(100.0)$ \\
$26-30$ & 13 & $13(100.0)$ & $13(100.0)$ & $13(100.0)$ \\
$31-35$ & 6 & $5(83.3)$ & $5(83.3)$ & $5(83.3)$ \\
$36-40$ & 5 & $5(100.0)$ & $4(80.0)$ & $5(100.0)$ \\
$41 \leq$ & 13 & $13(100.0)$ & $13(100.0)$ & $13(100.0)$ \\
\hline
\end{tabular}

Data are presented as number (\%).
Table 5. Cumulative Assignment of the Correct Diagnosis according to Number of Passes in Relation to the Size of the Lesion

\begin{tabular}{lcc}
\hline \multirow{2}{*}{ No. of passes } & \multicolumn{2}{c}{ Cumulative correct diagnosis } \\
\cline { 2 - 3 } & $\begin{array}{c}\text { Size of lesion } \\
(\leq 20 \mathrm{~mm}) \\
(\mathrm{n}=31)\end{array}$ & $\begin{array}{c}\text { Size of lesion } \\
(>20 \mathrm{~mm}) \\
(\mathrm{n}=45)\end{array}$ \\
\hline 1 & $20(64.5)$ & $42(93.3)$ \\
2 & $23(74.2)$ & $44(97.8)$ \\
3 & $24(77.4)$ & $44(97.8)$ \\
4 & $24(77.4)$ & $44(97.8)$ \\
No. of passes for diagnosis & $1.21 \pm 0.50(1-3)$ & $1.05 \pm 0.21(1-2)$ \\
p-value & \multicolumn{2}{c}{0.09} \\
\hline
\end{tabular}

Data are presented as number (\%) or mean \pm SD (range).

Table 6. Univariate and Multivariate Analysis of Variables Associated with Obtaining a Correct Diagnosis

\begin{tabular}{|c|c|c|c|c|}
\hline \multirow{2}{*}{ Variable } & \multicolumn{2}{|c|}{ p-value } & \multirow{2}{*}{ OR } & \multirow{2}{*}{$95 \%$ CI } \\
\hline & Univariate & Multivariate & & \\
\hline Needle size (22-gauge vs 19-gauge) & 0.180 & 0.326 & 3.07 & $0.33-28.83$ \\
\hline \multicolumn{5}{|l|}{ Puncture route } \\
\hline Transgastric (vs the other routes) & 0.731 & - & - & - \\
\hline Transduodenal (vs the other routes) & 0.434 & - & - & - \\
\hline Size of lesion ( $\leq 20 \mathrm{~mm}$ vs $>20 \mathrm{~mm}$ ) & 0.014 & 0.040 & 9.92 & $1.11-88.78$ \\
\hline \multicolumn{5}{|l|}{ Location of lesion } \\
\hline Lymph node (vs the other lesions) & 0.941 & - & - & - \\
\hline Submucosal tumor (vs the other lesions) & 0.666 & - & - & - \\
\hline Pancreatic mass (vs the other lesions) & 0.489 & - & - & - \\
\hline No. of needle passes (1 vs $2-4$ ) & 0.895 & - & - & - \\
\hline
\end{tabular}

$\mathrm{OR}$, odds ratio; $\mathrm{CI}$, confidence interval.

number of needle passes required for diagnosis of lesions with a diameter of $>20$ and $\leq 20 \mathrm{~mm}$ (Table 5). Slightly more passes $(1.21 \pm 0.50$; range, 1 to 3$)$ were required for lesions with a diameter of $\leq 20 \mathrm{~mm}$ than for those with a diameter of $>20 \mathrm{~mm}$ $(1.05 \pm 0.21$; range, 1 to 2$)$; however, no significant difference was noted $(\mathrm{p}=0.09)$. In addition, the mean lesion size of the patients who could not be diagnosed was $21.0 \pm 4.8 \mathrm{~mm}$, whereas it was $32.1 \pm 17.0 \mathrm{~mm}$ in those who could be diagnosed, showing that the lesion size of the patients who could not be diagnosed was significantly small ( $\mathrm{p}=0.034)$.

Based on these findings, size of lesions $(\leq 20 \mathrm{~mm})$, puncture needle size, puncture route, location of lesions, and number of passes were assessed as potential factors affecting correct diagnosis by univariate analysis, and size of lesions $(\leq 20 \mathrm{~mm})$ was identified as an independent factor $(\mathrm{p}=0.014)$. In addition, multivariate analysis was performed on puncture needle size (22-gauge) showing a p-value of $\leq 0.2$ in the univariate analysis. Size of lesions ( $\leq 20 \mathrm{~mm}$ ) was thus identified as an independent factor that affected correct diagnosis $(\mathrm{p}=0.040$; odds ratio, 9.92;
95\% confidence interval, 1.11 to 88.78 ) (Table 6).

\section{DISCUSSION}

In addition to its high diagnostic yield, EUS-FNA is safe and minimally invasive, and thus has been popularized rapidly. The procedure is currently being established as one of the standard diagnostic modalities for pancreatic tumors, gastrointestinal submucosal tumors, and lymph node lesions. However, most reports that have described its excellent performance to date are from high-volume centers, and a number of issues remain to be overcome for general hospitals to enjoy the same performance. In addition to technical factors, samples that can be obtained by EUS-FNA are particularly small, and thus, understanding of the pathology department is also an important element. In the diagnosis of an EUS-FNA sample, a close collaborative relationship between an endoscopist and a highly experienced cytopathologist is essential, particularly when rapid on-site cytological examination is performed. ${ }^{6}$ However, there is a shortage of cy- 
topathologists in general hospitals, particularly in the provinces, and thus, facilities that can perform rapid on-site cytological examination are limited. Thus, a close collaboration to obtain a better understanding of the condition may be very difficult in actual clinical settings. To overcome these obstacles, collection of biopsy samples that can withstand histological diagnosis was attempted. ${ }^{7}$ If tissue structures are preserved in a sample, the possibility of obtaining a more absolute diagnosis is high and immunostaining also becomes easy. Such a sample is useful particularly in the differentiation of benign diseases and diagnosis of lymphoma and submucosal tumors, which are often difficult to diagnose by cytologic diagnosis. The Quick-Core ${ }^{\circledR}$ needle (Cook Medical Inc.), which is a Trucut needle, was developed on the basis of the concept that intact, undamaged tissues could be collected. However, the needle is considerably strong and difficult to bend, making puncture procedures generally difficult. Moreover, puncture at the site of the scope angle is often problematic and therefore has not gained wide popularity. ${ }^{7,8}$ Considering these issues, the same manufacturer developed PN. PN is stainless and the stylet is made of nitinol, making it soft with improved operability. Moreover, the size of the Trucut needle was only 19-gauge, whereas PN is manufactured in three sizes: 19-, 22-, and 25-gauge, from which selections can be made depending on the site of the lesion and the puncture route. The major characteristic is the side hole close to the tip of the puncture needle called "Core Trap," which is based on "reverse bevel technology." When the needle is pulled by hand, the tissue is scraped thus facilitating its collection. To date, investigations on the usefulness of PN have reported several cases (Table 7). ${ }^{9-}$

${ }^{14}$ In all reports, the success rate was $96.4 \%$ to $100 \%$ and the overall correct diagnoses were $75 \%$ to $96 \%$, which are satisfactory results. Three SN-controlled randomized studies have been reported. ${ }^{10,13,14}$ In the investigation involving pancreatic tumors conducted by Bang et al., ${ }^{10}$ no significant differences were observed in the procedure success rate, diagnostic yield, and safety between the two puncture needles. However, Hucl et al. ${ }^{13}$ found no significant differences in sensitivity, specificity, PPV, NPV, and accuracy but did find that the mean number of needle passes needed to obtain ample tissue was 2.5 times for SN and 1.2 times for PN, showing a significant difference $(p<0.001)$. They reported that with $\mathrm{PN}$, fewer punctures were required to reach a diagnosis and therefore was useful in shortening the puncture procedure time. Moreover, even in the investigation ${ }^{11}$ that assessed the diagnostic yield of a single puncture, the reported correct diagnosis was $88.5 \%$, which was a favorable result. Furthermore, in our investigation, correct diagnosis was 89.5\%. Moreover, the mean number of needle passes that enabled diagnosis was 1.1 , which was a similarly good result. The fact that diagnosis is possible with fewer punctures can be expected to not only shorten the puncture procedure time but also improve cost-effectiveness. In addition, the percentage of successful histologic diagnosis was reported to be $75 \%$ to $89.5 \%{ }^{9-12,14}$

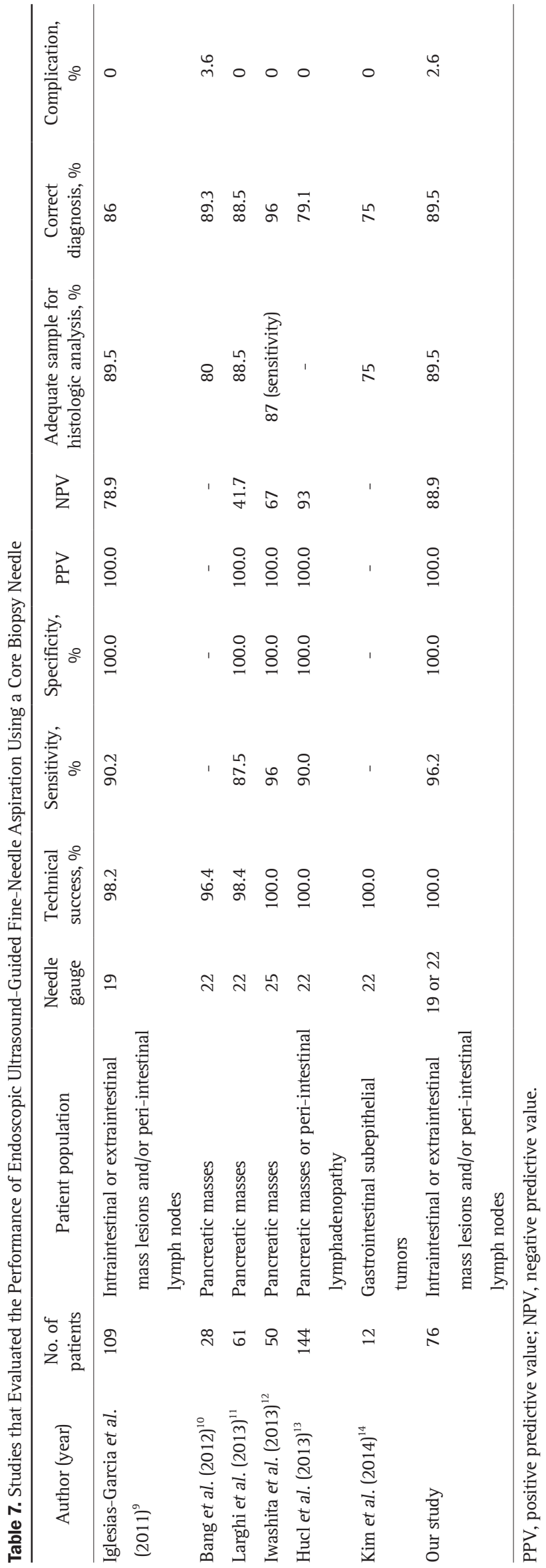


which was also satisfactory. In the present study, the samples that allowed histological examination could be obtained from all but two patients whose samples were assessed by cytologic diagnosis alone, and thus, histological diagnosis was possible in $89.5 \%$ of the samples. From these results and the characteristics of the puncture needle, the usefulness appear to be even higher in facilities where rapid on-site cytological examination is not available and the properties of a sample could not be judged with each puncture, such as ours in particular.

With regard to puncture needle size, investigations of 19-gauge, ${ }^{9} 22$-gauge, ${ }^{10,11,13,14}$ and 25 -gauge ${ }^{12}$ have been reported, but there has been no report on the comparison of the sizes of PN. Favorable results were reported for all puncture needle sizes. However, Iglesias-Garcia et al. ${ }^{9}$ reported that with the 19-gauge needle, transduodenal puncture was slightly difficult, and the puncture procedure could not be completed in two cases. In this study, the procedure success rate for both 19- and 22-gauge needles was $100 \%$. This is presumable because 22-gauge was selected from the beginning of the procedure when operability of the puncture needle was predicted to be poor in the EUS observation. Moreover, the diagnostic yield of the 19- and 22-gauge needles were compared in this study, but no significant differences in the sample collection rate, histologic diagnosis possibility rate, and correct diagnosis were observed.

The safety of EUS-FNA has been established and the complication rate is low at approximately $1 \%$ to $2.5 \% .{ }^{15}$ In reports to date on PN, while Bang et al. ${ }^{10}$ reported one case of mild acute pancreatitis, no other complications have been reported. In our study, there were two patients with intraluminal bleeding, but both cases were mild and improved conservatively. It seems that with the "reverse bevel technology". There is also a risk of injuring blood vessels when removing the puncture needle. However, in reports to date, the safety does not appear to be different from that of SN.

In the present study, diagnostic yield significantly decreased in cases with lesion sizes of $\leq 20 \mathrm{~mm}$. To date, the correlation between diagnostic yield and lesion size in PN has not been reported, although it has been investigated for SN. In EUS-FNA of lesions with a small size, an accurate procedure is generally required and the level of difficulty often increases. ${ }^{16}$ In a report on pancreatic tumors, tumor sizes of $\leq 20$ and $\geq 21 \mathrm{~mm}$ have been comparatively investigated, and the respective sensitivities were $75 \%$ and 94\%, indicating a significant difference. ${ }^{17}$ However, more recent reports often state high rates of correct diagnosis regardless of lesion size because of advancements in devices and establishment of technologies. When lesion sizes were classified into $\leq 20,20-30$, and $\geq 30 \mathrm{~mm}$ to compare sensitivity, the respective rates were reported as $86 \%, 81 \%$, and $83 \% .{ }^{18}$ Even with sizes of $\leq 10 \mathrm{~mm}$, the rate of correct diagnosis was reported to be $96 \%$, which was very good, suggesting that even with small lesion sizes, the diagnostic yield did not change. ${ }^{19}$ In the present study, technical factors could not be ruled out as a reason for the significant decrease in diagnostic yield when the lesion size was $\leq 20 \mathrm{~mm}$. However, PN has a characteristic tip form of having a side hole, which also possibly contributed to the decrease. In this study, we made the effort to keep the side hole inside the lesion in order to take advantage of the characteristics of PN and to prevent contamination from the side hole. When the tip of PN was measured (Fig. 1), the length from the tip to the proximal end of the side hole was 9 and $5.9 \mathrm{~mm}$ in the 19- and 22-gauge needles, respectively. With this unique structure, when the inside of the target lesion was stroked, the distance available for the strokes are shorter by at least 9 and $5.9 \mathrm{~mm}$ with the 19and 22-gauge needles, respectively, compared with SN. Based on calculations, when a 19-gauge PN is used for a lesion with a size of $10 \mathrm{~mm}$, the stroke inside the lesion can reach only $1 \mathrm{~mm}$ of the lesion. Although it is difficult to generalize because the lesion size varies with the margin and puncture surface, strokes will be certainly limited compared with SN. In particular, larger margins must be employed for submucosal tumors suspected of GIST, wherein there is a concern for tumor rupture if penetrated, and lesions behind and to which blood vessels are adjacent, and this tendency may become marked in these cases. However, even when the side hole is outside the lesion, it may be possible to make an adequate diagnosis with a sample collected from the end hole. If the effects of factors such as contamination are

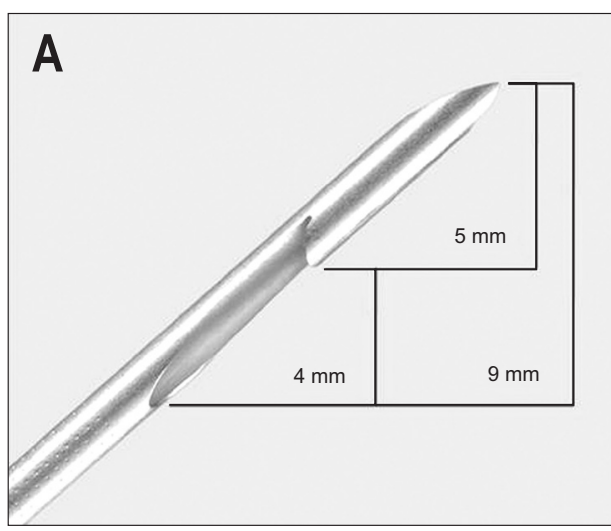

19-Guage

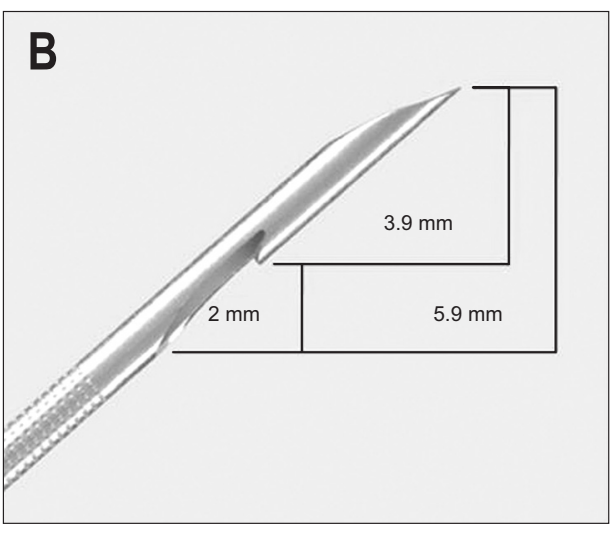

22-Guage
Fig. 1. Detailed image of the tip of the 19-gauge (A) and 22-gauge (B) ProCore ${ }^{\mathrm{TM}}$ needle (Figure supplied by Cook Medical Inc.). 
insignificant enough to be ignored, use of a long stroke length rather than keeping the side hole inside the lesion may lead to better diagnostic performance for small lesions.

The present study has some limitations. First of all, it is a single-center, retrospective case study. Secondly, the investigation was conducted on a single group, and SN was not employed as a control. Therefore, analysis of the correlation between size of lesions and diagnostic yield is limited to comparison with previous reports, and it is not possible to definitively conclude whether the decreased diagnostic yield for small lesion is unique to PN. There is a need to confirm the findings of the present study in a prospective, multicenter, SN-controlled, randomized study involving a large number of subjects.

In the present study, EUS-FNA using PN has been shown to be very safe and similar to SN. Its diagnostic yield has also been determined to be good. In most of the patients, diagnosis was possible using a single puncture. Except for two patients, histologic diagnosis was adequately conducted. In particular, the procedure was suggested to be highly useful in differentiating benign diseases, which are generally difficult to assess by cytologic diagnosis, and diagnosis of lymphoma and submucosal tumors, where immunostaining is often necessary. On the other hand, the diagnostic yield of EUS-FNA significantly decreased with lesion sizes of $\leq 20 \mathrm{~mm}$. This is likely related to the presence of a side hole in the structure, and further investigation is necessary.

\section{CONFLICTS OF INTEREST}

No potential conflict of interest relevant to this article was reported.

\section{REFERENCES}

1. Vilmann P, Jacobsen GK, Henriksen FW, Hancke S. Endoscopic ultrasonography with guided fine needle aspiration biopsy in pancreatic disease. Gastrointest Endosc 1992;38:172-173.

2. Eloubeidi MA, Chen VK, Eltoum IA, et al. Endoscopic ultrasoundguided fine needle aspiration biopsy of patients with suspected pancreatic cancer: diagnostic accuracy and acute and 30-day complications. Am J Gastroenterol 2003;98:2663-2668.

3. Yoshinaga S, Suzuki H, Oda I, Saito Y. Role of endoscopic ultrasound-guided fine needle aspiration (EUS-FNA) for diagnosis of solid pancreatic masses. Dig Endosc 2011;23 Suppl 1:29-33.

4. Itoi T, Sofuni A, Itokawa F, Irisawa A, Khor CJ, Rerknimitr R. Current status of diagnostic endoscopic ultrasonography in the evaluation of pancreatic mass lesions. Dig Endosc 2011;23 Suppl 1:17-21.

5. Wang KX, Ben QW, Jin ZD, et al. Assessment of morbidity and mortality associated with EUS-guided FNA: a systematic review. Gastrointest Endosc 2011;73:283-290.
6. Jhala NC, Jhala DN, Chhieng DC, Eloubeidi MA, Eltoum IA. Endoscopic ultrasound-guided fine-needle aspiration: a cytopathologist's perspective. Am J Clin Pathol 2003;120:351-367.

7. Panic N, Larghi A. Techniques for endoscopic ultrasound-guided fine-needle biopsy. Gastrointest Endosc Clin N Am 2014;24:83107

8. Thomas T, Kaye PV, Ragunath K, Aithal G. Efficacy, safety, and predictive factors for a positive yield of EUS-guided Trucut biopsy: a large tertiary referral center experience. Am J Gastroenterol 2009;104:584-591.

9. Iglesias-Garcia J, Poley JW, Larghi A, et al. Feasibility and yield of a new EUS histology needle: results from a multicenter, pooled, cohort study. Gastrointest Endosc 2011;73:1189-1196.

10. Bang JY, Hebert-Magee S, Trevino J, Ramesh J, Varadarajulu S. Randomized trial comparing the 22-gauge aspiration and 22-gauge biopsy needles for EUS-guided sampling of solid pancreatic mass lesions. Gastrointest Endosc 2012;76:321-327.

11. Larghi A, Iglesias-Garcia J, Poley JW, et al. Feasibility and yield of a novel 22-gauge histology EUS needle in patients with pancreatic masses: a multicenter prospective cohort study. Surg Endosc 2013;27:3733-3738.

12. Iwashita T, Nakai Y, Samarasena JB, et al. High single-pass diagnostic yield of a new 25-gauge core biopsy needle for EUSguided FNA biopsy in solid pancreatic lesions. Gastrointest Endosc 2013;77:909-915.

13. Hucl T, Wee E, Anuradha S, et al. Feasibility and efficiency of a new 22G core needle: a prospective comparison study. Endoscopy 2013;45:792-798.

14. Kim GH, Cho YK, Kim EY, et al. Comparison of 22-gauge aspiration needle with 22-gauge biopsy needle in endoscopic ultrasonography-guided subepithelial tumor sampling. Scand J Gastroenterol 2014;49:347-354.

15. Eloubeidi MA, Tamhane A, Varadarajulu S, Wilcox CM. Frequency of major complications after EUS-guided FNA of solid pancreatic masses: a prospective evaluation. Gastrointest Endosc 2006;63: 622-629.

16. Binmoeller KF, Rathod VD. Difficult pancreatic mass FNA: tips for success. Gastrointest Endosc 2002;56:S86-S91.

17. Agarwal B, Abu-Hamda E, Molke KL, Correa AM, Ho L. Endoscopic ultrasound-guided fine needle aspiration and multidetector spiral CT in the diagnosis of pancreatic cancer. Am J Gastroenterol 2004;99:844-850.

18. Volmar KE, Vollmer RT, Jowell PS, Nelson RC, Xie HB. Pancreatic FNA in 1000 cases: a comparison of imaging modalities. Gastrointest Endosc 2005;61:854-861.

19. Uehara H, Ikezawa K, Kawada N, et al. Diagnostic accuracy of endoscopic ultrasound-guided fine needle aspiration for suspected pancreatic malignancy in relation to the size of lesions. J Gastroenterol Hepatol 2011;26:1256-1261. 